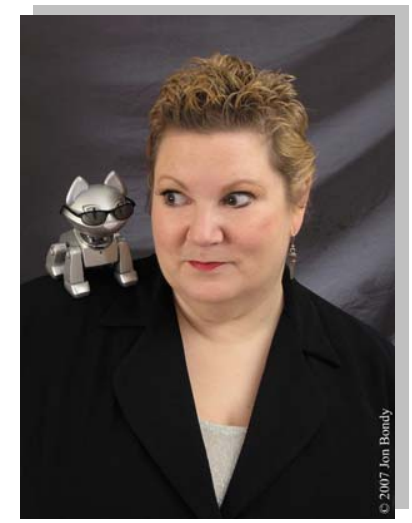

\section{Information Literacy in} Real Life and in Second Life By Cybèle Elaine Werts

Back in the years of yore when I was a student at Temple University, I took a batch of communications classes in pursuit of my degree in video

production. In one of the more esoteric ones, we often debated the meaning of media literacy as it related to the media of the time, circa early 1980's. Did such a concept even exist? If so, what was it, and was it even relevant to our work? At the time, the consensus was no.

Today, the debate on that existence and relevance has been made moot by thirty years and a proliferation of information so vast, it's nearly immeasurable. I was typing those youthful term papers on a portable electric typewriter which was pretty nifty at the time because it had an automatic correction function, and it is to my PC today that same vast, nearly immeasurable distance. Today, we all see the results of what we call information, or perhaps technological literacy (broadly speaking). You may not know exactly what these phrases mean yet, but they affect your ability to get a job, buy a house, pay your bills, and so much more.

What is Information Literacy then? What about Media Literacy, Visual Literacy and the rest? Are they the same, part of a continuum or just some Big Amorphous Blob?

Let's look at some definitions before we move on. Just so you know, there are as many definitions for these phrases as there are students with esoteric communications degrees, so I selected the ones that are short, concise, and have an excellent provenance.

\section{Visual Literacy}

Based on the idea that visual images are a language, visual literacy can be defined as the ability to understand and produce visual messages. This skill is becoming increasingly important with the everexpanding proliferation of mass media in society. As more and more information and entertainment is acquired through non-print media (such as television, movies and the Internet), the ability to think critically and visually about the images presented becomes a significant skill. Visual literacy is something learned, just as reading and writing are learned. It is very important to have the ability to process visual images efficiently and understand the impact they have on viewers.

$\sim$ AT\&T/UCLA Initiatives for 21st Century Literacies ${ }^{1}$

\section{Information Literacy}

Information Literacy is defined as the ability to know when there is a need for information, to be able to identify, locate, evaluate, and effectively use that information for the issue or problem at hand.

$\sim$ National Forum on Information Literacy ${ }^{2}$

\section{Digital Literacy}

Digital literacy is more than just the technical ability to operate digital devices properly; it comprises a variety of cognitive skills that are utilized in executing tasks in digital environments, such as surfing the web, deciphering user interfaces, working with databases, and chatting in chat rooms. $\sim$ Eshet-Alkali \& Amichai-Hamburger ${ }^{3}$

\section{Media Literacy}

Media Literacy is a twenty-first century approach to education. It provides a framework to access, analyze, evaluate and create messages in a variety of forms - from print to video to the Internet. Media literacy builds an understanding of the role of media in society as well as essential skills of inquiry and self-expression necessary for citizens of a democracy. 
Now just as a side note, and perhaps an appetizer to encourage you to read my interview with Tamara Moats on the Visual Thinking Process (VTP) which she uses in her work as a museum curator in teaching students how to see art in a new and different way. I asked her how she saw visual thinking as part of the larger scope of Information and Visual Literacies that we're exploring here. Tamara gave me not the pedagogical definition, but one more from the heart. She said:

"I see it as something that pervades all aspects of the contemplative life. Art is a reflection of society, of a people, of an individual. It is a pathway to the soul. It stimulates us to think, even for just a few minutes, in a new way, and in that sense, open new pathways in the mind.... It is about the experience, either sensual or rational, and whatever message we might gain from it. The idea of visual literacy has become important currently because we are so bombarded with imagery every waking moment. It is important to become visually literate, or visually discerning, in order to survive.”

I include her perspective here because it's easy to get lost in the practical applications of all this literacy stuff, and forget that it is also entirely engaged in the way that we move through the world.

With this in mind, allow me to invite you to step back a little and see if we can get a grasp on how all these concepts, definitions, and spirals of fancy come together in a real life way. One place they all come into play is in Second Life (SL) where I have recently begun my explorations through my Avatar named SuperTechnoGirl. SL is a fine example of the confluence of all these types of literacies, although perhaps not "real life" as you may define it. On the one hand, it uses a conceptual framework that allows us to look at the world of SL in a visual and spatial way as we are used to doing in real life such as walking around. For example, when you go shopping in SL, you may teleport to the store, but you'll actually “walk” through each room of the store, just as you would in real life. This is important because we all need building blocks of the familiar before we can move on to the unfamiliar. On the other hand, SL also requires us to move through space, conduct business, and interact with other people (Avatars) in a way that is completely novel.

Second Life is not simply a game where you go to play and win or lose. In fact, it's not a game at all, and there's nothing in particular to win or lose. Of course I'm sure that there are some people who do go there just to goof around, flirt, or maybe to spend hours designing clothing or some such. And I'm sure there are some games there as well if you were to seek them out. But let's face it, most of us don't have the time, interest, or motivation to spend our life that way.

Think of Second Life instead as a place to do what you do in real life, but through your computer. Take me as an example, being as I'm the only one here. Aside from my interest in cool boots, I like to hang out with other writers, information professionals, and people into emerging technologies. On the one hand, just exploring SL is a shot at my goal of learning new technologies, and where better to meet those info pros than say at the Special Libraries Association SL space? SL describes it as allowing organizations to create space for communication, collaboration and community engagement. You can hold virtual meetings and classes, construct product

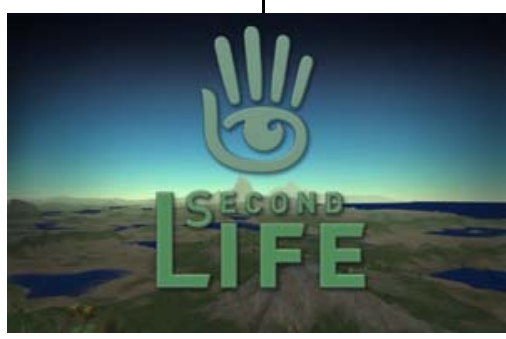
simulations, provide employee training and more.

There is also real business being transacted (I've spent about \$20 US so far, which actually buys quite a lot there), visited a number of stores that 
most definitely do not exist in

Vermont, and sat on a

beautiful beach and watched

the waves crash against my

wicker chair as I listened to the sounds of the surf. Is it all imaginary? Well, it depends on how philosophical you want to get. Ideas and information aren't "real" in the sense of being concrete, but they are certainly authentic enough. Second Life is another place although not a traditional "place” as we generally define it - to explore, live, learn, and play. It is another reality that is as existent as ideas and creativity, and of course if you have the right skills - as with all things - there's money to be made.

Let's talk a little about how Information and the other literacies come into play here because I'll tell you, SL actually is rather a challenge to learn, and if I didn't have all of my literary ducks in a row, I would have long since given up. (I still sometimes consider it.)

\section{Visual Literacy in SL}

SL is almost completely a visual medium, although of course if you're a wee bit tech-savvy, friends can chat with you by voice (microphone and speaker), or through digital transformations of their typed words. The downside of this intensely visual side of things is that often as in life, how we look is unfortunately almost more important than who we are. In my first few discussions with various SL participants, I heard more comments about my lack of taste in hair and clothing than I ever heard about who I was, what I did for a living, or anything else that actually means anything. The interesting thing is that in the real world, I'm sure these same people would never have the nerve to criticize me out loud. I'm almost thinking I'd rather live in real life and not hear it when it comes to this, but whatever.

I was annoyed as you can imagine, although I had a vague feeling it had something to do with that "you're in or you're out” group mentality. I was clearly "new" so I also was clearly "out" with some groups where that was important (not groups where I was likely

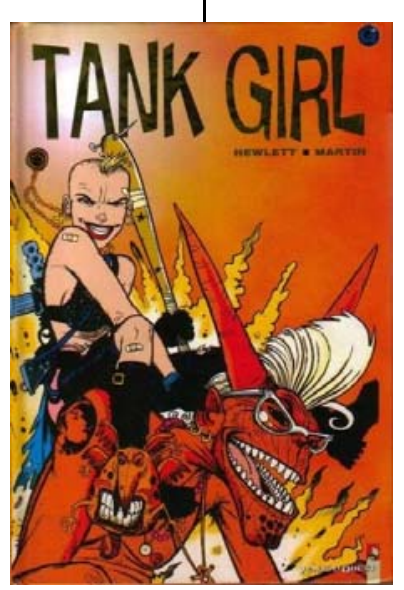

to return). Although I gave it back to the Nasty Parkers with a few choice remarks, I nevertheless felt a bit embarrassed that I'd entered a universe where the clothes available were considered Goodwill leavings. I trotted off to do some shopping and picked up some groovy duds, which fortunately are pretty darn cheap in a virtual world. And yes, you do pay real money even for virtual clothing unless you have the skills to design them, which I do not. Of course you can also earn money in SL which are called Linden Bucks, but that's a whole other discussion.

Aside from my petty grumbling, the broader implications of this are actually quite interesting. My Avatar - SuperTechnoGirl - looks like a more hard-bodied version of me, except with red hair which I always wished I had. I wasn't aiming for anything exotic. In SuperTechnoGirl is a lot of me (Cybèle), and some of who I want to be: a tough gal with rippled abs. (Try not to laugh!). In truth, nearly everyone online is not only fabulously gorgeous, has spectacular clothing, sports killer hair, and is of course - thin. Look around you now - how many people are like that? No, I mean really! The ones who aren't those things usually have Avatars who are exotic animals from Mars or something of the sort. SL allows us to be anyone we want, which is fun, but also means that there are none of the limits of real life. When I look at the people I'm meeting and speaking with, I can't help but wonder how much of their Avatar is really them (as I am Cybele) and how much is who they want to be (the abs). And also, is your fantasy self (Say if I wanted to be Tank Girl for a day) any less real than my little fantasy about being more buff? Try to figure out that little philosophical conundrum. Of course, when you think about it, we all kind of got stuck with the looks and bodies we were born with, and how we look may well have zip to do with who we are anyway. The result is that we can't really trust anything we see or hear from another person in SL, relative to how many of us see "truth" in everyday life. It's all a little squirrelly don't you think? 
Visual Literacy extorts us to think critically about what we see, and attend to learning about the environment in which we are moving through. It asks us to process visual images efficiently and understand the impact they have, because in places like SL, not doing so nets you a whole lotta nothing. Come to think of it, not doing so in real life nets you a whole lotta nothing as well.

\section{Information Literacy in SL}

Information Literacy asks us to identify, locate, evaluate, and effectively use the information we need. In the world of SL, this is a pretty big stipulation, because it's not just about getting a better "Do" or a really terrific pair of boots. In navigating around, there is, for example, the simple act of moving your Avatar from one place to another, either by walking, flying, and even teleporting - my favorite method because it's pretty much Captain Kirk's Transporter. How do you learn to walk, fly, or teleport? Where is that information? I ask because in SL there is the website (http://secondlife.com/) which has all kinds of information and help, but then there's also the actual software Second Life which is a completely separate application which you install and run when you want to travel in. Yup, it took me a while to get this one straight, and both of them offer help and advice in completely different ways.

Locating the right information and translating that to the situation at hand has not always been an easy task. Walking, flying and teleporting I got. Buying a snazzy outfit I even got, although it took a fair bit longer than browsing the real life Silhouettes online catalogue. But I still haven't figured out why the hair I bought in SL has a big bald spot in the back, and how to fix that. The reason I can't fix that is because the seller sent me a document on correcting the problem, but I can't figure out how to download the document, presuming that I
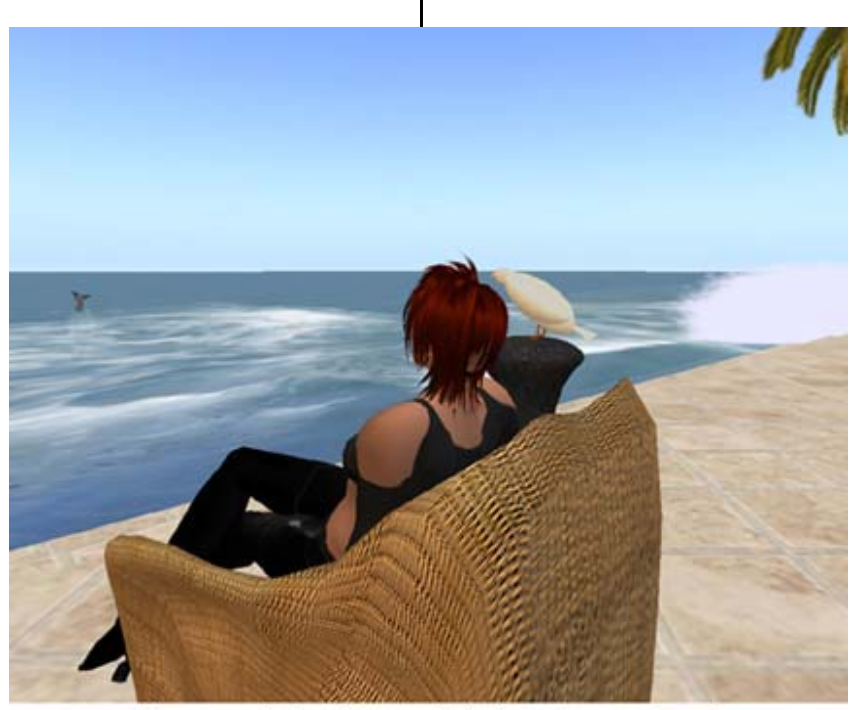

SuperTechnoGirl on one of the Second Life beaches. even have the capacity to undertake the operation whatever it is. Oh, and then there's the problem that I can't reply directly to e-mails from the seller via SL. It's so frustrating that I've given up until I can suck up enough caffeine one morning to cope with it. Translation: my Information Literacy for Second Life is on an exceedingly slow learning curve. I know I have the need; I have more or less identified and located the information required (about the hair), but I can't effectively use it. As to evaluating, well that's a place to teleport to another day entirely.

\section{Digital Literacy in SL}

Here's the good part: I'm pretty down with Digital Literacy; which is a blessing from the CyberGods after that soap opera with the hair. If there is anything I can do, it's "executing tasks in digital environments, such as surfing the web, deciphering user interfaces, working with databases, and chatting in chat rooms.” On the chat room side I had a few interesting experiences, mostly in that people were about as interested in me as they were in real life; meaning that they pretty much could care less. Ongoing "chats" in the various places I visited was pretty much the same as any chat room you might visit in ten thousand places on the Internet: silly, flirtatious conversation that overlaps and generally makes little sense. Lots of "insider" comments which also make no sense. The only real difference is that I could see everyone standing around in cool outfits, leaning against brick walls with a James Dean attitude. Some even smoked. I wonder if they get cyber lung cancer? And as I mentioned, one hundred percent of the people in the rooms I visited were visually stunning in one way or another. If that isn't the key to know how much is imaginary, I don't know what is. I will say that a few (a very few) friendly souls chatted with me and sent me a variety of items, including skins (I think that's hair or clothing or something), landscapes (places to visit) and of 
course lots of recommendations for clothing and hair stores.

I've always been proud of my ability to learn new applications fairly quickly, and I think I'm doing pretty well with SL in general. What I am reminded to do is to use my skills, not so much to struggle through the morass myself, but rather to research the Internet for some training in Second Life. Note to Self: Contact the SLA group in SL for advice. After all, if my sister librarians can't help me, who can?

\section{Media Literacy in SL}

If Media Literacy is not a stale conversation from the 1980's, what is it? On the other hand, the definition of Media Literacy does specify "twentyfirst century approach,” and my days at Temple were definitely in the old $20^{\text {th }}$ century. Perhaps then it translates, for example, into the recent two-part free training sessions that the Special Libraries Association (SLA) and Click University hosted using WebEx (webcasts) and then a live session in Second Life. That's the new millennium part of Media Literacy we can get down with. The "media" part of this literacy is the variety of ways that we have to learn now, whether it be those webcasts or live SL sessions, podcasts, video clips, online training modules, or even - gasp - old fashioned printed documents like I'm hand editing in bleeding red ink right now. How tres passé! The most important part of every tool however, is how it is matched to the need. Yes, I like to edit my own stuff on paper with red ink - just like editors did in the good old days. But no, that sure doesn't work when you're editing a journal with a co-editor. When I send things to my co-editor Jacqueline, it is of course always electronic.

Then as now I see resistance to these changes even in my own workplace. Colleagues want their work methods to stay the same, to stay as it was when we were typing on that nifty portable

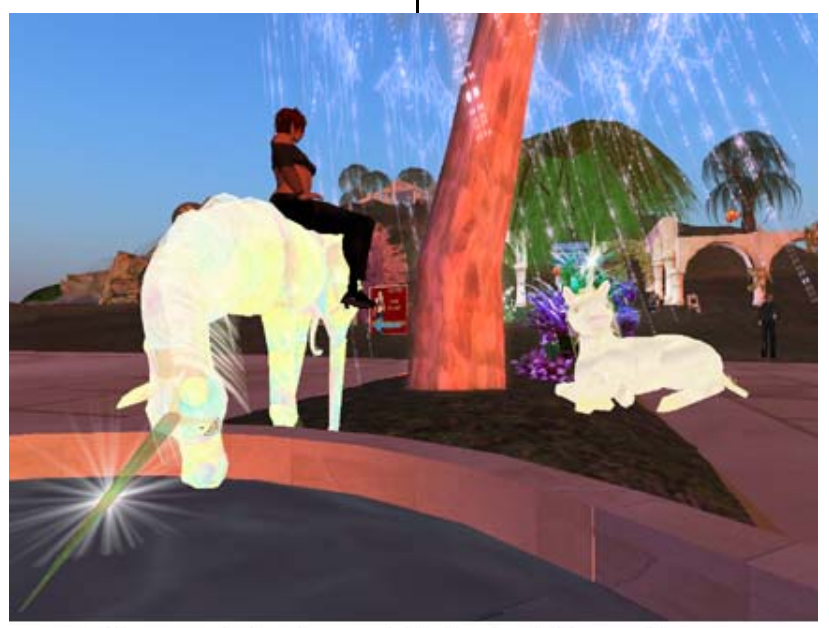

SuperTechnoGirl visiting the Unicorns on the Isle of Tranquility at Second Life
I've been thinking lately of teleporting via Second Life back to my communications class at Temple University and chatting up that young girl who was me about all the fun stuff that's happening these days in Media Literacy, but she probably wouldn't believe me. After all, even the 1984 dawn of the Macintosh was still a year away. But then even SL doesn't allow for time travel as far as I know. Still, teleporting around as 
in "Beam Me Up Scottie" has always been a dream of mine, so if I can't do it here in Vermont, at least SuperTechnoGirl can do it on the Isle of

Tranquility. One of my favorite experiences was when I flew over the island and spotted a water fountain with two glistening unicorns. I spent about half an hour figuring out how to hop up on one and sit down - kind of sidesaddle was the best I could do. But once I got there I have to admit, it was a beautiful place. It's that kind of view that brings me back to Second Life. Fortunately, SuperTechnoGirl has more Information Literacy in her little finger than I ever had in my whole arm; although I'm not so sure about the hair.

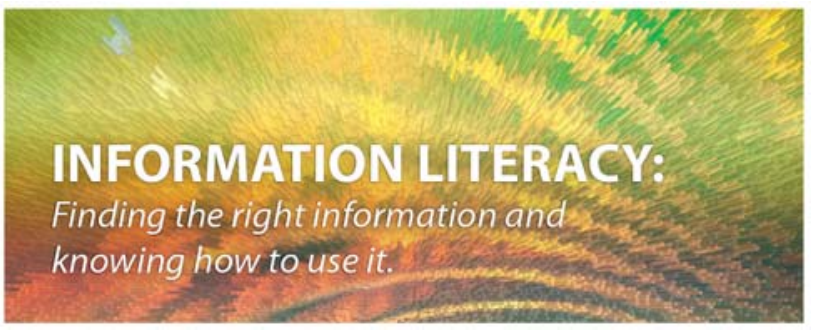

\section{References}

1. "Media Literacy Definition Matrix." Leadership Summit Toolkit 200730 Sep 2008

$<$ http://www.setda.org/web/guest/toolkit2007/medial iteracy/definitionmatrix $>$.

2. Ibid

3. Ibid

4. "Visual Literacy." AT\&T/UCLA Initiatives for 21st

Century Literacies 06/20/2002 20 Sep 2008

http://www.kn.pacbell.com/wired/21stcent/visual.html

\section{Other Resources}

\section{Second Life}

Second Life ${ }^{\circledR}$ is a 3-D virtual world created by its Residents. Since opening to the public in 2003, it has grown explosively and today is inhabited by millions of Residents from around the globe. From the moment you enter the World you'll discover a vast digital continent, teeming with people, entertainment, experiences and opportunity. Once you've explored a bit, perhaps you'll find a perfect parcel of land to build your house or business. You'll also be surrounded by the Creations of your fellow Residents. Because Residents retain intellectual property rights in their digital creations, they can buy, sell and trade with other Residents. The Marketplace currently supports millions of US dollars in monthly transactions. This commerce is handled with the inworld unit of trade, the Linden ${ }^{\mathrm{TM}}$ dollar, which can be converted to US dollars at several thriving online Linden dollar exchanges.

http://secondlife.com/

\section{SLA in Second Life Blog}

Sharing learnings and initiatives around SLA in Second Life.

http://sla-divisions.typepad.com/sla_in_second_life/

\section{Tank Girl - the Film}

http://en.wikipedia.org/wiki/Tank_Girl_(film

\section{Information Literacy Competency Standards for Higher Education}

These standards were reviewed by the ACRL Standards Committee and approved by the Board of Directors of the Association of College and Research Libraries (ACRL) on January 18, 2000, at the Midwinter Meeting of the American Library Association in San Antonio, Texas. These standards were also endorsed by the American Association for Higher Education (October 1999) and the Council of Independent Colleges (February 2004)

Read a full version of the standards http://www.ala.org/ala/mgrps/divs/acrl/standards/standards.pdf

\section{The Standards Are:}

1. The information literate student determines the nature and extent of the information needed.

2. The information literate student accesses needed information effectively and efficiently. Standard Three

3. The information literate student evaluates information and its sources critically and incorporates selected

4. information into his or her knowledge base and value system.

5. The information literate student, individually or as a member of a group, uses information effectively to accomplish a specific purpose.

6. The information literate student understands many of the economic, legal, and social issues surrounding the use of information and accesses and uses information ethically and legally.

\section{Reference:}

http://www.ala.org/ala/mgrps/divs/acrl/standards/inform ationliteracycompetency.cfm 